\title{
EL ASESINATO DE PRIM A TRAVÉS DE LA PRENSA ESPAÑOLA DE FINALES DE 1870*
}

\author{
PRIM'S MURDER THROUGH THE SPANISH PRESS AT THE END OF 1870 \\ O ASSASSINATO DE PRIM NA IMPRENSA ESPANHOLA DO FIM DE 1870.
}

\author{
DIEGO CAMENO MAYO** \\ Universidad Complutense de Madrid \\ https://doi.org/10.46553/EHE.23.1.2021.p23-38
}

\begin{abstract}
Resumen
El atentado que acabó con la vida del que fuera presidente del Consejo de Ministros, Juan Prim y Prats (1814-1870), continúa siendo un misterio. Todavía hoy se discute acerca de la identidad y modus operandi de los que organizaron, financiaron e instigaron el crimen. Este trabajo se centra en el análisis de la prensa del momento con el único objetivo de saber qué detalles se conocían en los instantes inmediatamente posteriores al suceso y cómo se transmitían a la sociedad española.
\end{abstract}

\section{Palabras clave}

Prim - Crimen - Prensa -Información -Noticias

\begin{abstract}
The attempt that finished with the life of the president of the Council of Ministers, Juan Prim y Prats (1814-1870), continues being a mystery. The identity and the modus operandi of those who organized, financed and instigated the crime are still under discussion. This work is focus on the analysis of the press of the moment of the crime with the aim of analysing the known details moments just after the attempt occurred and how this information was transmitted to the Spanish society.
\end{abstract}

Palabras clave

Prim - Crime - Press -Information -News

\section{Resumo}

O atentado que pôs fim à vida do ex-presidente do Conselho de Ministros, Juan Prim y Prats (1814-1870), permanece um mistério. Ainda hoje, a identidade e modus operandi daqueles que organizaram, financiaram e provocaram o crime estão a ser discutidos. Este trabalho centra-se na análise da imprensa do momento com o único objetivo de saber quais detalhes eram conhecidos nos instantes imediatamente após o evento e como eles foram transmitidos para a sociedade espanhola.

Palavras chave

Prim - Crime - Imprensa - Informação - Notícias 


\section{Introducción}

La muerte del general Juan Prim y Prats, conde de Reus y marqués de los Castillejos con Grandeza de España, ha mantenido una serie de interrogantes, rumores y leyendas que afloraron en el mismo instante de su fallecimiento y se perpetuaron hasta nuestros días. Se ha querido ver su origen en la coacción que sufrieron los escritores y periodistas de la España de finales del XIX para no desvelar información comprometedora. El temor a señalar a poderosos personajes y el partidismo político provocaron que, aunque el rostro del autor del crimen fuese conocido por todos, jamás se escribiese su nombre. ${ }^{1}$

Algunos de estos tempranos cronistas han sido fuente principal de muchos historiadores contemporáneos. ${ }^{2}$ Nada de malo habría en ello de no ser porque, de esta manera, se han repetido mitos que poco o nada tienen que ver con lo que realmente sucedió y esto tampoco ayuda a esclarecer los hechos. Así, por ejemplo, los escritos de Pérez Galdós -muy queridos por los historiadores ${ }^{3}$, no pueden ser tomados al pie de la letra ya que, de forma novelada, reprodujo la versión oficial de la época, evitando poner por escrito datos relevantes que parecía conocer. ${ }^{4}$

El paso del tiempo conlleva, como es lógico, la desaparición de los personajes implicados, atenuando -aunque no eliminando- los miedos e intereses de los escritores. Este hecho tiene su parte positiva, y es que permite abordar la cuestión con la necesaria perspectiva histórica. No obstante, este artículo pretende acercarse a la realidad de la época, valiéndose para ello de los escritos que los periodistas del momento publicaban en los distintos medios. Con ello se busca conocer y analizar la visión que se tuvo del crimen en los días inmediatamente anteriores y posteriores al suceso.

\section{La prensa española en el Sexenio Democrático (1868-1874)}

En el instante en el que estalla la Revolución Gloriosa o Septembrina (septiembre de 1868), la prensa española se halla en una coyuntura complicada. Los últimos años del reinado de Isabel II se caracterizaron por la limitación de la libertad de expresión y el cierre de periódicos. Hasta tal punto llegaba la restricción, que existía un buen número de ciudades españolas de cierta entidad que carecían de prensa. ${ }^{5}$ El triunfo de la revolución supuso un cambio drástico en este sentido. La prioridad del nuevo Gobierno fue la libertad de imprenta, la suavización de las penas para los delitos de prensa y las facilidades para la creación de nuevas publicaciones. ${ }^{6}$ En estas circunstancias, no es de extrañar que la

\footnotetext{
* Fecha de recepción: 05/04/2019. Fecha de aceptación: 04/06/2020

** Investigador predoctoral en Universidad Complutense de Madrid, https://orcid.org/0000-0003-12046236, Dirección: Facultad de Geografía e Historia, Universidad Complutense, C/ Profesor Aranguren s/n, 28040, Madrid, España, dcameno@ucm.es.

${ }^{1}$ RUBIO, 2017, 496-497; y PEDROL RIUS, 199041.

2 DE DIEGO, 2014; PÉREZ ABELLÁN, 2014; GIBSON, 2013; DONÉZAR, 2016; FAERNA, 2014; ANGUERA, 2003; OLIVAR BERTRAND, 1975; ROBLEDO y KOUTSOURAIS, 2014; POCH NOGUER, 1934; RUEDA VICENTE, 2000; FONTANA BERTRÁN, 2013; VILCHES GARCÍA, 2014; JIMÉNEZ ESCOLANO, 2014; DE CÉSPEDES ARÉCHAGA, 2015; CALVO POYATO, 2011; LÓPEZ AZORÍN, 2015; ninguna de estas obras señala, rotundamente y sin reparos, la identidad del (o los) asesinos.

${ }^{3}$ Como demuestra la obra de DONÉZAR, op. cit.

${ }^{4}$ Pío Baroja afirmó que Galdós le contó lo que sabía sobre el atentado, pero se disgustó mucho con él cuando vio que el canario no publicó nunca su historia, sino que se ciñó a la versión oficial. Cuando a Baroja le preguntaron cuál era esa versión de Galdós, respondió que no la recordaba bien; DONÉZAR, op. cit., 574. En su obra, Javier Rubio cuenta otra versión del episodio entre Baroja y Galdós; RUBIO, op. cit., 507.

${ }^{5}$ CHECA GODOY, 2006, 19.

${ }^{6}$ Sobre el número de publicaciones disponibles durante el Sexenio véase CHECA GODOY,
} 
prensa española conociese durante el Sexenio Democrático un crecimiento excepcional e incomparable con otros periodos de nuestra Historia. ${ }^{7}$ Además, a todo esto contribuyó la estrecha relación entre la política y la prensa. ${ }^{8}$

Todos los medios consultados tenían como sede la capital de España. La razón no solo se encuentra en que esta fue la ciudad en la que se cometió el crimen, también está en su número de publicaciones y relevancia. En 1870, Madrid edita, aproximadamente, un cuarto de la prensa total de España, entre la que se cuentan los periódicos más importantes del país. ${ }^{9}$ A grandes rasgos, las noticias no suelen variar de un medio a otro; encontrando muchas de ellas reproducidas en todos los periódicos consultados, independientemente de su orientación política. Las grandes diferencias se pueden observar en el tratamiento que cada diario otorga a las informaciones que publican y el sentido que cada uno de ellos le da. Tampoco estarán ausentes las discusiones y polémicas entre distintos medios, los datos erróneos o contradictorios, las suspicacias de unos y el sentimentalismo - en ocasiones fingido o exagerado- de otros. En definitiva, el crimen de la calle del Turco, pese a la reprobación general, se convirtió en un arma arrojadiza con la que poder atacar al rival político. Antes de viajar al año 1870, convertidos en lectores y lectoras de prensa, es necesario señalar qué publicaciones han sido elegidas y por qué. El objetivo principal de este trabajo es cubrir todo el espectro político, consultando los diarios más significativos de cada opción, desde los medios tradicionalistas hasta los órganos más radicales del republicanismo español. ${ }^{10}$

Empezando por los medios más cercanos al carlismo, ha sido consultado el periódico La Esperanza, creado en octubre de 1844, de edición vespertina. En palabras de Checa Godoy este era "el único diario en rigor confesadamente carlista" y el séptimo periódico con más audiencia en todo el país. ${ }^{11}$ Tras este se cuenta La Época, diario creado en abril de 1849, vespertino y que se mantuvo fiel a la dinastía borbónica, cambiando su apoyo de Isabel II a su hijo, el futuro Alfonso XII. ${ }^{12}$ Sin embargo, el más consultado por los lectores españoles -superando los 40.000 ejemplares vendidos- fue La Correspondencia de España, creado en octubre de 1848 y que contó con varias ediciones a lo largo de su historia. Diario cercano al partido unionista (Unión Liberal, liderada por O’Donnell hasta su muerte en 1867), aunque posteriormente se posicionase a favor de la candidatura al trono del duque de Montpensier. ${ }^{13}$

Dentro de los medios progresistas (afines al Gobierno) han sido analizados La Iberia (diario matutino) y El Imparcial (varias ediciones). El primero de ellos comenzará el Sexenio como uno de los medios más leídos de España, sin embargo, en 1867 se creará

op. cit., 36-37. Almuiña y Delgado Idarreta incidieron en esa libertad otorgada por las nuevas autoridades: DELGADO IDARRETA, 2000, 250.

${ }^{7}$ No obstante, no hay que olvidar que el Gobierno no hizo nada para detener a grupos, como la célebre "partida de la porra" (con apoyo gubernamental), que se dedicaban a extorsionar (llegando incluso al asesinato) a periodistas críticos con el poder. CHECA GODOY, op. cit., 20-22.

${ }^{8}$ Ibidem., 29-32.

${ }^{9}$ Ibidem., 87.

${ }^{10}$ Cada partido político dispondrá de varios órganos de prensa en Madrid, siendo difícil encontrar un medio independiente que no responda a los intereses de ningún grupo político. Ibidem., 89.

${ }^{11}$ Ibidem., 59 y 106.

12 Ibidem., 65-66.

${ }^{13}$ Ibidem., 41 y 89. Antonio de Orleans, duque de Montpensier, hijo del rey de Francia, Luis Felipe I de Orleans, y marido de la hermana de Isabel II, Luisa Fernanda. Tiempo antes del derrocamiento de Isabel II ya ambicionaba ser coronado rey de España, por lo que colaboró con los revolucionarios de 1868. Pese a contar con el apoyo de ciertos sectores militares y políticos, el general Prim nunca le consideró seriamente como candidato al Trono. Este hecho despertó el odio y la oposición de Montpensier, hasta el punto de ser considerado uno de los sospechosos principales del atentado que acabó con la vida de Juan Prim. GARCÍA RODRÍGUEZ, 2015; ROS, 2000; y FERNÁNDEZ ALBÉNDIZ, 1998. 
El Imparcial, más a la izquierda y que, rápidamente, ocupará «el segundo lugar entre los periódicos madrileños, lo que en la época equivale a decir españoles» (con unos 30.000 ejemplares vendidos), mientras que La Iberia pasará a ser un periódico secundario. ${ }^{14}$

Dentro de la prensa demócrata-republicana, La Discusión, (suspendido en 1866 tras la sublevación de San Gil y reaparecido en octubre de 1868 en edición matutina) era uno de los periódicos más importantes de Madrid. En esta época se convertirá al republicanismo, alejándose de los demócratas "cimbrios" que aceptaron la Monarquía. ${ }^{15}$ Más a la izquierda se hallaba La Igualdad, órgano madrileño de los republicanos federales que también vieron una notable expansión durante el Sexenio, siendo este uno de los medios más estables vinculados a esta ideología política. Pese a carecer del carácter informativo de otros periódicos (como El Imparcial o La Correspondencia de España), fue uno de los más influyentes. ${ }^{16}$ En relación al general Prim, La Igualdad no dejó de atacarlo hasta su muerte, ejerciendo siempre una dura oposición. Por último, El Combate, fue publicado tan solo los meses finales del año 1870. Este diario, más radical que $L a$ Igualdad, siempre hizo honor a su nombre, puesto que fue uno de los periódicos más

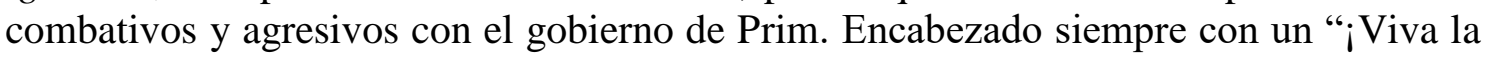
República Democrática Federal!”, fue dirigido por el diputado José Paúl y Angulo, uno de los sospechosos principales de perpetrar el crimen de la calle del Turco. ${ }^{17}$

Ahora sí es momento de viajar a los últimos días de 1870, empleando estos diarios para reconstruir lo que sucedió -o pudo suceder-en la calle del Turco y, posteriormente, en la residencia de Juan Prim, el palacio de Buenavista, hasta su funeral en los primeros días de 1871.

\section{Madrid, 28 de diciembre de 1870}

El día 28 de diciembre de 1870, la capital de España amanecía con las primeras noticias acerca del atentado cometido la noche anterior. Diversos artículos trataban el atentado de la calle del Turco, empezando por aquellos que mostraban la importancia de lo sucedido (que monopolizaba conversaciones en cualquier lugar público) hasta los que hacían referencia al estado de salud del Presidente. Llama la atención que, en la misma página de un periódico, se pudiesen leer dos noticias contradictorias: el Parte Oficial del Ministerio de la Gobernación afirmaba que las heridas -ya tratadas- no presentaban complicación alguna, mientras que otro texto del propio diario contaba que las lesiones que sufría el conde de Reus ponían en riesgo su existencia. De esta manera, La Esperanza era uno de los pocos periódicos que publicaba este informe médico el día 28 de diciembre de 1870. Los redactores de este medio, decidían abandonar su oposición política al gobierno de Prim y condenaban duramente el crimen cometido. También informaba acerca de la sustitución del general herido por el unionista Juan Bautista Topete, colaborador de Prim en la Revolución Gloriosa de $1868 .^{18}$

Al igual que la mayoría de periódicos de la época, La Esperanza recogía dos noticias aparecidas en La Iberia y El Imparcial para informar a sus lectores acerca del crimen

\footnotetext{
${ }^{14}$ CHECA GODOY, op. cit., 39 y 89. El Imparcial competiría por ese segundo puesto con Las Novedades.

${ }^{15}$ Ibidem., 43.

${ }^{16}$ La Igualdad distribuye casi el doble de ejemplares en toda España que otros medios como La Discusión: más de 15.000 ejemplares frente a los 8.000 de La Discusión. Es más, será el tercer periódico más vendido en todo el país. Ibidem., 48-51, 92 y 97.

${ }^{17}$ La Iberia y La Discusión tuvieron ediciones de mañana y tarde, mientras que La Igualdad comenzó como periódico vespertino pero, posteriormente, pasó a publicarse por las mañanas.

${ }^{18}$ La Esperanza, 28 de diciembre de 1870, 2-3
} 
cometido. ${ }^{19}$ Así, transcribía amplios relatos extraídos de los dos periódicos más afectos al partido de Juan Prim, (rivales políticos de los que hacían posible este diario). Es necesario detenerse en esto porque se puede concluir que el objetivo de La Esperanza no era mostrar la repulsa generalizada que había provocado el inicuo acontecimiento; más bien pretendía transmitir a sus lectores una información lo más detallada posible, para lo cual juzgaban a El Imparcial y La Iberia como los medios mas competentes para ello. No erraban el tiro los periodistas de La Esperanza, ya que estos dos diarios fueron los que mas información ofrecieron a los lectores. La Iberia, publicaba un artículo titulado "CRIMEN INAUDITO". ${ }^{20}$ En ese texto se presentaban los acontecimientos que habían tenido lugar la tarde anterior, condenaban el atentado, tranquilizaban a la población y, además de ensalzar al ilustre herido, hacían un elogio al verdadero pueblo español, que no es asesino, salvaje ni revoltoso sino honorable y amante de la libertad, por lo que condenaría el atentado y apoyaría al Gobierno. Posteriormente, en la misma página, se ampliaba la información relativa a lo acontecido en la calle del Turco, brindando una descripción de lo que sucedió (o pudo suceder) en dicha calle. Hasta en cuatro ocasiones se podía leer que las heridas del general no revestían gravedad alguna e incluso se afirmaba que en pocos días estaría recuperado. Sin embargo, el general -aunque levedecidió nombrar sustituto a Topete para poder recuperarse de sus lesiones sin tener que ocuparse de las cuestiones políticas del país. Dos ideas principales se podían extraer en estos primeros momentos leyendo La Iberia: la primera es que el general se hallaba levemente herido, incluso había sido intervenido con éxito y se encontraba tranquilo, y la segunda es que el pueblo se había lanzado a las calles para conocer el estado del ilustre herido, que recibía múltiples muestras de cariño, ahuyentado con ello los posibles fantasmas de la revolución. Esas revueltas parecían inquietar a los periodistas de $L a$ Iberia, que confiaban en el Gobierno, apoyado en la lealtad que le brindaba la mayoría del pueblo, al que le pedía enérgica respuesta contra esos asesinos que, a día 28, parecían haber escapado. Interesante es también la reflexión que mostraba este periódico en su segunda página. Haciendo gala de un recelo digno del mejor detective, llegaba a afirmar que la presencia en Madrid de sospechosos forasteros, avisos y movimientos extraños en los aledaños del Congreso la tarde anterior y demás "coincidencias raras" podían tener algo que ver con el atentado. No obstante, como ya se ha afirmado, confiaban plenamente en el Gobierno y en la Justicia.

A su vez, La Esperanza tomaba de El Imparcial una mayor abundancia de datos que hacían referencia a lo que sucedió en la calle del Turco y, posteriormente, en el palacio de Buenavista; además, se trataba la huida de los asesinos -con caballos esperándoles en el Prado- y la sospechosa actuación de los agentes del orden público, que no hicieron acto de presencia en ningún momento en la zona donde se perpetró el crimen. ${ }^{21}$

La crónica presentada por El Imparcial es muy interesante porque ofrecía una serie de datos que, convertidos en leyenda o refrendados por la historiografía, han llegado hasta

\footnotetext{
${ }^{19}$ Exactamente lo mismo hacían otros diarios, como el conservador La Época o el republicano La Igualdad, que el 28 de diciembre, sin mucha información relativa al crimen, tan solo copiaban las informaciones aparecidas en dichos medios (que consideraba serios y sensatos). Además, la información relativa al suceso se ofrecía a partir de la página 3, reflejando menor interés por el acontecimiento que otros medios. El demócrata La Discusión se movía en una línea similar a este último, dedicando apenas una columna a tratar las noticias relacionadas con el atentado del día anterior y reproduciendo, literalmente, el suplemento que el diario El Imparcial publicaba unas horas antes.

${ }^{20}$ La Iberia, 28 de diciembre de 1870, 1.

${ }^{21}$ Ibidem. La Época también se dio cuenta de esta oscura maniobra y no dejaba pasar la ocasión de criticar al Gobierno por haber disminuido la capacidad de acción de la policía, aprovechando tan triste momento para pedir la restitución de los agentes de orden público, cuya acción habría evitado la tragedia. La Época, 28/12/1870, 2-3.
} 
nuestros días. El primero hacía referencia al grito del ayudante del general Prim, el coronel Moya: "Bájese, V., mi general, que nos hacen fuego". ${ }^{22}$ Algunos autores varían las palabras y otros hasta las ponen en boca del otro asistente del general, Ángel González Nandín, pero ahí continúa, casi un siglo y medio después. ${ }^{23}$ Otro hecho que se relataba en este artículo era el que hacía referencia a los latigazos que el cochero de la berlina propinó a los asesinos, algo que, en opinión de Pedrol Rius, sí se puede considerar leyenda. ${ }^{24}$

La Época era otro medio que condenaba rotundamente el atentado hasta el punto de señalar a periódicos republicanos, como La Igualdad, que, en su opinión, no habían reprobado el crimen con suficiente contundencia. La intención subyacente en las noticias de La Época parecía ser la de querer mostrar a sus lectores cómo prácticamente toda la prensa había condenado duramente el atentado. ${ }^{25}$ Además de esto, La Época se hacía eco de otras informaciones, como el bando publicado por el gobernador civil de Madrid, Ignacio Rojo Arias -en el que condenaba el crimen y apelaba al civismo del pueblo, pidiendo confianza en el Gobierno y prometiendo la salvación del orden social establecido-.

\section{Madrid, 29 de diciembre de 1870.}

A lo largo del jueves 29 de diciembre, el estado de salud de Prim y las noticias relativas a la detención de sospechosos, coparon las páginas de diarios como La Esperanza, La Época, El Imparcial o La Discusión. Si la evolución médica del herido no parecía quedar clara a la luz de las informaciones transmitidas, distinto era el caso de los encarcelamientos. ${ }^{26} \mathrm{El}$ lector podía encontrar, en cualquier medio, la lista de los arrestados: el inspector del distrito de Congreso, Sr. Valencia, dos taberneros, un detenido en la calle Quintana, otro que fue denunciado por un guarda de los jardines de la Cuesta de la Vega, un italiano y dos conductores de carruajes. También se detallaban los desperfectos sufridos por el efecto de las balas en la ropa y coche del general Prim y en la misma calle del Turco, donde se agolpaban los curiosos, cerrando estas informaciones con la publicación del bando del gobernador civil, Rojo Arias. ${ }^{27}$

En un artículo titulado "LA PRENSA", El Imparcial ofrecía una recopilación de todas las noticias publicadas en relación con el crimen de la calle del Turco. Su finalidad no era otra que mostrar la relevancia del trágico acontecimiento, así como la reprobación unánime del suceso. Para este último fin se dividían los periódicos según su ideología, desde los progresistas y democráticos hasta los montpensieristas, pasando por los alfonsinos. Se demostraba la repulsa que el vil atentado había suscitado en todo el

\footnotetext{
${ }^{22}$ Ibidem. Otros diarios también publicaban versiones similares de lo que pudo suceder en la calle del Turco.

${ }^{23}$ Este detalle está lleno de contradicciones y las versiones varían ostensiblemente de un autor a otro. Véase R. OLIVAR BERTRAND, op.cit., 534; DONÉZAR, op. cit., 552; ANGUERA, op. cit., 2003, 614. Es necesario recalcar la importancia de esta frase ya que, en opinión de Javier Rubio, puede ser empleada como prueba definitiva e inculpatoria de sospechosos como José Paúl y Angulo. RUBIO, op. cit., 647-648. ${ }^{24}$ PEDROL, op. cit., 39.

${ }^{25}$ La Época, 28 de diciembre de 1870, 2-3.

${ }^{26}$ Como ejemplo baste citar la información publicada por La Época, que aseguraba que la evolución médica era favorable y satisfactoria, aunque reconocía que "la convalecencia del general Prim tendrá forzosamente que ser larga y penosa". La Época, 29 de diciembre de 1870, p. 3. El Imparcial, La Iberia y La Discusión eran más optimistas, llegando a afirmar que el diagnóstico era muy favorable y que las heridas sufridas por el general no eran "ni tantas ni tan graves como se creía".

${ }^{27}$ Muchas de estas noticias aparecerán reproducidas exactamente en los días posteriores en los siguientes diarios: La Iberia, 30 de diciembre de 1870, 1; La Discusión, 30 de diciembre de 1870, 3; La Igualdad, 30 de diciembre de 1870, 3, y 31 de diciembre de 1870, 2.
} 
espectro político, así como en las distintas clases sociales. Esta idea estaba muy alejada de la expuesta, ese mismo día, por La Discusión, monopolizada por el atentado de Prim y sus repercusiones en el país. En primer lugar, artículos como "GRAVEDAD DE LA SITUACIÓN" y algunos que le sucedían, dejaban claro que los republicanos no estaban conformes con la nueva situación política, al mando del brigadier Topete, y con las noticias de restringir las libertades en España. ${ }^{28}$ Más allá iba La Igualdad, diario en el que brillaba por su ausencia la condena del atentado; mucho más preocupado por denunciar la falta de competencia de las autoridades locales y fuerzas del orden público. A pesar de todo, ofrecía al lector un resumen de todas las noticias relacionadas con el atentado. Este hecho no llama excesivamente la atención; lo llamativo se encuentra en su conclusión esta sí firmada por los periodistas de La Igualdad-en la que se reconocía la condena por parte de los periódicos de todas las ideologías y orientaciones políticas, pero se sorprendían por la poca oposición que había tenido la propuesta de La Iberia, que pedía al Gobierno adoptar medidas extraordinarias. ${ }^{29}$

En todo momento se dejaba clara la postura y preocupación de La Igualdad en relación al atentado, pero más patente se hacía aún si se tiene en cuenta el artículo titulado "CAÍDA DEL PROGRESISMO". ${ }^{30}$ En él, se criticaba duramente la elección de Topete, ("¡un unionista!"), como sustituto de Prim y se auguraba una preocupante decadencia del Partido Progresista que, sin su líder, estaba abocado a la desaparición. Como nota final, aún tenía tiempo La Igualdad para defenderse de aquellos que acusaban a los republicanos de estar detrás del crimen de la calle del Turco. ${ }^{31}$

\section{Madrid, 30 de diciembre de 1870}

El caudal de noticias del día 30 seguía la misma tónica. La Esperanza informaba a sus lectores sobre el estado de salud del general Prim, que se hallaba estable, aunque con fiebre de gran intensidad. La Época y La Iberia apuntaban en la misma dirección: la vida de Prim, pese a sufrir graves lesiones, no corría peligro. La Discusión, aunque ofrecía el mismo diagnóstico, recordaba que, aunque la evolución era satisfactoria, el estado del general era grave. ${ }^{32}$

En cuanto a los trabajos de detención de los conjurados, este diario ampliaba las informaciones que apuntaban hacia la detención del italiano y de un individuo que fue sorprendido con un trabuco en las inmediaciones de la residencia de Manuel Ruiz Zorrilla, miembro del Partido Progresista que había detentado la cartera de Justicia bajo el mandato de Prim. Esta labor policial no contentaba a los redactores de La Época, que continuaban denunciando el escaso celo que mostraban, últimamente, las fuerzas de orden público. En su opinión, esta policía hacía tiempo que no desempeñaba su función con la necesaria competencia y eso solo se explicaba por la política del Gobierno, que no dejaba actuar a los agentes. Es más, parecía que había sospechas de que esa noche Prim iba a sufrir un atentado y, aun así, las autoridades no habían sido capaces de cumplir con su deber. ${ }^{33}$

Pese a las críticas, las investigaciones seguían su curso y se decía que el propio Prim había dado pistas acerca de apariencia de uno de los conspiradores. Según el general, el

\footnotetext{
${ }^{28}$ La Discusión, 29 de diciembre de 1870, 1.

${ }^{29}$ La Igualdad, 29 de diciembre de 1870, 2-3.

${ }^{30}$ Ibidem, 1.

${ }^{31}$ El malestar que produjo entre los republicanos la elección de Topete como sustituto de Prim, fue reforzado, un día más tarde, por sus colegas de La Discusión, 30 de diciembre de 1870, 1.

${ }^{32}$ La Discusión, 30 de diciembre de 1870, 1 y 3.

${ }^{33}$ La Época, 30 de diciembre de 1870, 3.
} 
asesino que rompió el cristal de su berlina era "alto y bien parecido". ${ }^{34}$ Esto no disipó las sospechas que se cernían sobre los republicanos ya que, el mismo día 30, La Época transcribía parte de una carta de un redactor del diario republicano radical El Combate, preso de la cárcel del Saladero, cuyo objetivo era exculpar a los redactores de dicho periódico y reprobar a los que les habían acusado. ${ }^{35}$

\section{Madrid, 31 de diciembre de 1870: ¡Prim ha muerto!}

El 31 de diciembre, España amanecía con la noticia de la muerte del Presidente. El fallecimiento, que tuvo lugar la tarde anterior, fue comunicado a los diputados reunidos en la sesión del 30 de diciembre, a través del discurso del ministro de Hacienda, Segismundo Moret. Los lectores tendrían ocasión de enterarse al día siguiente, de la mano de artículos como "PAZ A LOS MUERTOS", en el que La Esperanza despedía de forma solemne a su rival político. ${ }^{36}$ Mismo tono se apreciaba en La Época que, a su vez, elogiaba las palabras que Moret había dedicado al fallecido la noche anterior. En este diario, los españoles podían encontrar textos publicados por La Gaceta, en relación al agravamiento del general Prim y su penoso desenlace, (algo que también se copiaba de diarios como El Imparcial o El País, aunque este último opinase que el general se hallaba en estado crítico mucho antes y esa información se ocultó). También se informaba sobre los honores y mercedes concedidos tanto al ilustre fallecido como a su familia: el Ministerio de Gracia y Justicia otorgaba a la viuda el título de duquesa de Prim con Grandeza de España, además de elevar el marquesado de los Castillejos a ducado. La Época cerraba el año 1870 ofreciéndole al lector información relativa al entierro. ${ }^{37}$

El Imparcial aparecía con orla negra, de luto, y con un primer artículo dedicado a la trayectoria política de Prim, al dolor por su pérdida y a maldecir a los infames asesinos. ${ }^{38}$ Más adelante se transcribían los discursos, tanto del citado ministro, como del resto de diputados que expresaban su dolor por el fallecimiento del general. Antes de eso, ya en la primera página, se presentaba la sección de miscelánea política, monopolizada por el marqués de los Castillejos. En primer lugar, expresaban su dolor por la pérdida de uno de los hijos mas ilustres de la Patria. Un segundo artículo hacía referencia al efecto contraproducente del crimen, ya que había logrado que todos los españoles se uniesen en su dolor y apoyasen a don Amadeo por ser uno de los más notables logros del general; se publicaba también un artículo del periódico La República Federal en el que se condenaba el crimen de la calle del Turco, reforzando esa idea de repulsa nacida en todos los rincones del espectro político. El Imparcial daba también explicaciones al repentino fallecimiento del general: a las cuatro de la tarde su estado se agravó tanto que, en torno a las ocho de la noche tenía lugar el inevitable deceso. Prim se marchó rodeado de sus allegados, entre ellos su esposa, que también recibía palabras de consuelo.

En cuanto a las repercusiones políticas, este diario dejaba clara la postura de todos aquellos personajes con responsabilidades civiles y militares que, ante la noticia del fallecimiento, se prepararon para mantener el orden, en caso de que fuese necesario. Este último hecho muestra que los fantasmas de revueltas y algaradas continuaban acechando a la cúpula política del momento, tres días después del atentado.

\footnotetext{
${ }^{34}$ La descripción en La Esperanza, 30 de diciembre de 1870, 4; La Época, 30 de diciembre de 1870, 3; La Discusión, 30 de diciembre de 1870, 1; La Igualdad, 30 de diciembre de 1870, 3.

${ }^{35}$ Además de La Época, (3) otros diarios reproducían, a su vez, la carta del preso republicano: La Igualdad, 30 de diciembre de 1870, 2-3. Este último no solo publicaba el escrito, también daba la identidad del autor (Francisco Rispa Perpiñá) y brindaba todo su apoyo a los correligionarios acusados.

${ }^{36}$ La Esperanza, 31 de diciembre de 1870, 1.

${ }^{37}$ La Época, 31 de diciembre de 1870, 3.

${ }^{38}$ El Imparcial, 31 de diciembre de 1870, 1.
} 
La Iberia del 31 de diciembre también aparecía con edición de luto y con la triste noticia desde el principio: "Prim ha muerto". ${ }^{39}$ Antes de la crónica parlamentaria se podían leer dos columnas cargadas de sentimentalismo, la primera, solemne, dedicada a la memoria del héroe de los Castillejos y la segunda, titulada "LA CONDESA DE REUS", reflejando el dolor de la viuda y recordándole que los españoles estaban a su lado. Tras esas dos columnas, La Iberia recordaba que ya desde el día 27 llevaba pidiendo energía al Gobierno y a la Justicia para no dejar sin castigo tan infame crimen. Con la noticia del fallecimiento del general, los periodistas de este diario creyeron oportuno recordárselo a los políticos, jueces y pueblo español.

Distinto era el caso de La Discusión que no consideró oportuno incluir la orla negra en señal de luto por el malogrado general, ni siquiera la noticia de su muerte abría su edición. En la segunda columna, el lector podía informarse acerca del fallecimiento de la mano de una breve noticia en la que se aprovechaba para volver a condenar el crimen. Llama bastante la atención la escasa información que este diario dedicó a la muerte de Prim y más llamativas aún son una serie de noticias aparecidas en su página tres, en las que informaban acerca de la buena evolución que presentaban las heridas del general, ya fallecido en ese momento.

En una tónica similar al anterior, La Igualdad abría su número con dos artículos que, aunque no informaban de la muerte del prestigioso personaje, (cuya noticia no se daba hasta el último párrafo de la tercera columna y, además, lo hacía muy de pasada), guardaban estrecha relación con el atentado de la calle del Turco. El primero de ellos se preguntaba acerca de la nueva situación que se vivía en España, una calma tensa, un miedo a la revolución que inquietaba tanto al pueblo como a las autoridades. El segundo incidía, aún más, en la tesis de la caída del progresismo una vez que Prim desaparecía de escena. En esta misma página se podía leer información acerca del fallecimiento del conde de Reus, una noticia en la que se condenaba el crimen y se mostraban las condolencias de unos rivales que, si bien podían serlo en la arena política, recordaban con honor y respeto al héroe de los Castillejos. ${ }^{40}$

\section{Enero de 1871: la prensa tras el fallecimiento de Prim}

Tras el parón del día 1 de enero, La Esperanza volvía a publicarse el segundo día de 1871 y lo hacía mostrando un rifirrafe entre El País y El Imparcial. La causa de esta discusión no era nueva: muerto Prim, el progresismo quedaba muy debilitado y no podría sustentar, por sí solo, la corona de Amadeo de Saboya. La Esperanza opinaba de esta misma manera, algo que no era, en absoluto, del agrado de los progresistas; ${ }^{41}$ de hecho, el día anterior, El Imparcial presentaba una esquela en memoria del malogrado Prim y, acto seguido, hacía un llamamiento a la calma, (no en vano, el título de este artículo rezaba "SERENIDAD"). En ese texto, aunque admitía el duro golpe que suponía la muerte de Prim para el Partido Progresista, pedía sosiego y tranquilidad a los que pensaban que la muerte de Prim hería de muerte al progresismo. El otro diario oficial de este partido, $L a$ Iberia, atacaba duramente a quienes defendían esa teoría; El Imparcial continuaba por esa línea y pedía confianza a todos aquellos que recelaban de la vitalidad de un partido que acababa de perder a su indiscutible líder. ${ }^{42}$

\footnotetext{
${ }^{39}$ La Iberia, 31 de diciembre de $1870,1$.

${ }^{40}$ La Igualdad, 31 de diciembre de $1870,1$.

${ }^{41}$ La Esperanza, 2 de enero de 1871, 1.

${ }^{42}$ Es curioso cómo para defender esta idea llegan a basarse incluso en la Bolsa, que bajó 20 céntimos al conocerse la noticia del atentado, pero después se repuso, confiando en la sólida estructura que dejaba Prim edificada antes de su muerte. El Imparcial, 1 de enero de 1871, 1.
} 
No dejaba de ser protagonista $E l$ Imparcial, puesto que en la primera página de $L a$ Esperanza se recogía también una noticia que ese mismo periódico publicaba tras el fallecimiento del general. Esta publicación afirmaba que el estado de don Juan Prim siempre fue grave, pero se ocultó la información por altas razones de Estado, una mentira que no gustaba a La Esperanza y por la que pedía explicaciones. ${ }^{43}$

Otras noticias en relación al conde de Reus aparecidas en este número hacían referencia a una infame carta que habría recibido la viuda y en la que decía: "Nos hallamos muy satisfechos del éxito de nuestra obra y la continuaremos sin descanso". ${ }^{4}$

La información brindada por El Imparcial se completaba con una transcripción de un artículo titulado "EL ADVERSARIO LEAL", firmado por Eugenio García Ruiz. ${ }^{45}$ En él se alababa el bello texto que este personaje dedicaba al general Prim. Es interesante, porque este hombre era rival político del conde de Reus, lo que daba muestra de la postura de todos los hombres ilustres que, fuese cual fuese su ideología, se unían para condenar el crimen y rendir tributo al querido general.

Como es obvio, no iba El Imparcial a pasar por alto el aniversario de la batalla que encumbró al general Prim: la batalla de los Castillejos (01/01/1860), aprovechando la coyuntura para atacar a los criminales y lanzando una cuestión que invitaba a la reflexión: “Es esta la recompensa que España da a sus héroes?"46

De nuevo, se hacían abundantes referencias a la actitud de todos aquellos españoles que expresaban su profundo pesar y acudían a la residencia del general a mostrar su veneración y respeto. Es más, en este mismo número se afirmaba que la muerte del Presidente dio inicio a un intento de alteración del orden en la capital; sin embargo, la decidida acción de los gobernantes, así como la repulsa generalizada del crimen, evitaron posibles altercados. ${ }^{47}$

El Imparcial también se hacía eco de la información publicada en La Época y trataba de hacer una reconstrucción de la escena del crimen, basándose para ello en el testimonio de la esposa "de un médico muy conocido en Madrid" y sus hijos, todos ellos ocupantes de uno de los coches que se hallaban en la calle del Turco, impidiendo el paso de la berlina del general por encontrarse otro coche más. La noticia afirmaba que la obstrucción de los carruajes fue fortuita y no obra de los asesinos. La esposa del doctor también declaró haber escuchado el grito de "ahí viene, fuego" seguido de dos descargas. ${ }^{48}$ Es un testimonio importante y a tener en cuenta, pero no debe ser tomado sin reservas puesto que, aunque la testigo compareció ante la Justicia, hay detalles (como la teoría de los carruajes casualmente estacionados en la calle del Turco) que no parecen corresponderse con la realidad.

Por último, se publicaba una noticia en relación al general Serrano, al que Prim otorgó poco antes de morir: “(...) el título de Alteza, una pensión vitalicia de 25.000 duros

\footnotetext{
${ }^{43}$ La Iberia recogería esta información días más tarde. La diferencia estriba en que este último diario comparte y corrobora dicha noticia. Esto no deja de ser llamativo porque, además de reconocer que han publicado noticias que, por mucho que fuesen oficiales, eran falsas, refleja y reconoce -de nuevo- los temores de esas altas esferas del Estado. La Iberia, 4 de enero de 1871, 1.

${ }^{44}$ La carta fue publicada en diferentes diarios: La Esperanza, 2 de enero de 1871, 1; La Época, 2 de enero de 1871, 3; El Imparcial, 2 de enero de 1871, 2.

${ }^{45}$ El Imparcial, 1 de enero de 1871, 1.

${ }^{46}$ El Imparcial, 1 de enero de 1871, 2. La Iberia también recordaba esta efeméride con un artículo titulado “iiiCASTILLEJOS!!!”, La Iberia, 1 de enero de 1871, 1.

${ }^{47}$ El Imparcial, 1 de enero de 1871, 2.

${ }^{48}$ También La Igualdad se hacía eco de la información publicada por La Época acerca de la presencia casual de los coches en la calle del Turco la noche del atentado y la declaración de la esposa del eminente doctor. Pedrol Rius afirmó que, entre los testigos presenciales del crimen, se encontraba la esposa del doctor Vélez, cuyo testimonio se recogió en el sumario y coincide con lo publicado en prensa en 1871; PEDROL, op. cit., 67-69.
} 
y la propiedad de la casa que habita, (...)". ${ }^{49}$ Es curioso cómo este hecho ha significado para unos una fuente de recelo hacia Serrano mientras que, para otros, esta constituye una prueba fundamental para exculparle definitivamente de la sospecha de haber participado en la conjura. ${ }^{50}$

El nuevo año se recibía en La Iberia con orla negra y, además, encabezando su primer número de 1871 con una gran esquela en memoria de Prim. Seguidamente, se presentaba un artículo titulado "EL DEBER DE LOS PARTIDOS", en el que, además de reivindicar la figura del general, se llamaba a la unión de todos los liberales para guiar al nuevo rey, responsabilidad que recaía en ellos tras el fallecimiento de su líder, al que no podían fallar.

De poco servían los esfuerzos de La Iberia, ya que La Discusión recalcaba la complicada situación en que quedaba el progresismo una vez desaparecido su carismático líder, así como las inquietudes que les generaban a los republicanos que los progresistas, faltos de apoyos y liderazgo, se plegasen a los deseos de los unionistas. ${ }^{51}$

En una dirección similar apuntaban los republicanos que hacían posible La Igualdad. $\mathrm{Su}$ tesis no variaba con el paso de los días, y su vaticinio de la desaparición del progresismo se presentaba con mayor fuerza en el número del 1 de enero de 1871 . No se quedaba ahí, también informaba al lector -a través de noticias sacadas de otros periódicos- acerca de los últimos instantes de vida del general Prim, así como su complicación médica y fallecimiento. ${ }^{52}$ Es interesante también la inclusión de otra carta exculpatoria. Si días antes era Rispa Perpiñá, ahora Francisco Córdova y López se mostraba en la misma línea que su correligionario. Respondía duramente a las injurias, defendiéndose y negando cualquier participación de los republicanos radicales en el alevoso crimen. Quizá la frase que mejor resuma el contenido de la carta que publicaba La Igualdad sea la siguiente: "En una palabra, somos rebeldes, no conjurados."

\section{José Paúl y Angulo y El Combate}

Como hemos visto, desde que se tuvieron las primeras noticias del crimen, muchos señalaron a los republicanos como autores materiales o, al menos, como sospechosos principales. De todos ellos, el diputado jerezano, José Paúl y Angulo, fue el más mencionado. De hecho, La Esperanza informaba de la escasa confluencia en el Parlamento cuando se realizó el panegírico del ilustre fallecido, haciendo notar insistentemente la ausencia de Paúl. ${ }^{54}$

Desde 1870 hasta la actualidad no hay obra sobre el asesinato de Prim que no coloque al jerezano en el punto de mira; algo que el propio Paúl negó desde el primer momento. ${ }^{55}$

\footnotetext{
${ }^{49}$ El Imparcial, 2 de enero de 1871, 1.

${ }^{50}$ PÉREZ ABELLÁN, op. cit., 32-33 y RUBIO, op. cit., 681. La citada obra de Pérez Abellán suscitó una agria polémica con un grupo de historiadores que, incluso, llegó a los medios de comunicación. Para más información véase: CAMENO MAYO, 2019.

${ }^{51}$ La Discusión, 1 de enero de 1871, 1. Unos escritos que, como ya se observó, irritaron a los medios mas afectos al progresismo.

${ }^{52}$ Es interesante porque, según La Igualdad, es El Universal el diario que publicó la que sería la última frase pronunciada por Prim: "Hoy desembarca el rey y yo me muero. ¡Viva el rey!”. Una frase que, con ligeras variaciones, llegó a aparecer hasta en películas de cine. La Igualdad, 1 de enero de 1871, 3.

${ }^{53}$ La Igualdad, 1 de enero de 1871, 3.

${ }^{54}$ La Esperanza, 2 de enero de 1871, 3.

55 Ya en enero de 1871 La Igualdad publicaba una carta suya para condenar los ataques que se vertían sobre su persona. La Igualdad, 3 de enero de 1871, 2. Quince años después vería la luz su libro Los asesinos del general Prim y la política en España, en el que afirmaba probar "matemáticamente" su inocencia. En él señalaba que los republicanos (y él mismo) habían sido los chivos expiatorios del suceso (33), que aquellos que le acusaban eran unos calumniadores (127-146) o habían sido comprados, con la aquiescencia del
} 
Es cierto que las relaciones entre el jerezano y Prim se habían deteriorado hasta el extremo. Para concentrar y difundir sus mensajes de odio, Angulo decidió fundar un diario que llevaría por nombre El Combate. Este medio hizo gala, en prácticamente todas sus publicaciones, de un sentimiento de traición: los republicanos apoyaron la Revolución de 1868 pero siempre creyeron que fue traicionada. Se posicionaron en contra de la elección de Amadeo, a quien consideraron una forma más de atacar a la soberanía de la Nación, quedando ellos como únicos valedores de dicha soberanía. Esto les sirvió de excusa para llamar repetidamente al pueblo a la revolución.

El 23 de octubre de 1870 se anunció la futura publicación del nuevo diario, que vería la luz el 1 de noviembre de ese mismo año y que, con muy pocas excepciones, se publicaría diariamente hasta el 25 de diciembre de 1870 . Solo ojeando el primer número ya puede el lector darse cuenta de la línea que iba a seguir el periódico: “(...) no con palabras, sino con martillos, rompen los esclavos las cadenas que los oprimen; de que no con palabras, sino con bien templados aceros, se derriban las dinastías y los tronos; (...). $"$ "56

El general Prim sería uno de los protagonistas indiscutibles de este diario. Tildado de "anti-revolucionario", sufrirá numerosos calificativos y apodos por parte de los redactores de este periódico ${ }^{57}$ En este punto hay que señalar que su gobierno tampoco se libró de las iras de El Combate, en el que se vertían todo tipo de descalificaciones contra él. ${ }^{58}$ Atacar al Gobierno, descalificar e insultar a su líder, denunciar duramente lo que para ellos era una traición, erigirse en voz del pueblo oprimido o protestar contra todo aquello en lo que no creían (como la monarquía de Amadeo ${ }^{59}$ ) son actitudes que podemos considerar normales teniendo en cuenta que este diario fue el principal órgano de expresión del ala más radical del partido republicano federal. Todo lo expuesto anteriormente muestra la enemistad entre Paúl y Prim; pero no puede constituirse en prueba irrefutable de la participación del diputado jerezano en el magnicidio. No obstante, El Combate no se detuvo ahí y, en muchas ocasiones, fue un paso más allá. Sus llamamientos a la revolución fueron constantes, aunque tampoco esto condena definitivamente a Paúl y Angulo. ${ }^{60}$

Como es obvio, ninguno de los redactores de El Combate publicó nunca una amenaza de muerte expresamente contra Prim, aunque las proclamas revolucionarias y las llamadas a la violencia se complementaron con algunas frases más incendiarias que sí pueden interpretarse como intimidatorias. El 7 de noviembre de 1870, El Combate

propio juzgado instructor de la causa (91) y que los verdaderos culpables (el duque de Montpensier y el Regente en 1870, el general Serrano) jamás fueron molestados (125). PÁUL Y ANGULO, 1886.

${ }^{56}$ El Combate, 1 de noviembre de 1870, 1

${ }^{57}$ Calificativos como dictador, (El Combate, 18 de noviembre de 1870, 1), pequeño dictador, (El Combate, 12 de diciembre de 1870), amo Prim, (El Combate, 24 de noviembre de 1870, 3) y hasta bullanguero de Reus, (El Combate, 15 de noviembre de 1870, 2).

58 Artículos titulados de forma tan expresiva como “¡Abajo Prim!”, (El Combate, 30 de noviembre de 1870, 2), ya muestran esa oposición al marqués de los Castillejos que, prácticamente en todos los números de $E l$ Combate, era duramente criticado por ser el líder y personificación del Gobierno. Esta forma de tratar al general contrasta con lo expuesto años después por Paúl y Angulo que, en su obra exculpatoria, llegaba a afirmar que Prim le "estimaba mucho" y le "quería como a un hijo". PAÚL Y ANGULO, op. cit., 80.

${ }^{59}$ Todos los que trabajaban en este periódico eran republicanos, por lo que es obvio que no viesen con buenos ojos la llegada del duque de Aosta, (que tampoco se librará de los motes como el de rey Langosta, (El Combate, 26 de noviembre de 1870) al que también atacaron duramente, especialmente tras el 16 de noviembre, fecha en la que tuvo lugar la votación que lo convirtió en Rey electo de los españoles.

${ }^{60}$ Junto con los ataques al Gobierno y a la Gloriosa, las amenazas y convocatorias a la revolución son muy numerosas en El Combate, 2 de noviembre de 1870, 1; 11 de noviembre de 1870, 2; 25 de noviembre de 1870, 2; "La Revolución es necesaria", 3 de diciembre de 1870, 1; 10 de diciembre de 1870, 1; 14 de diciembre de 1870, 15 de diciembre de 1870, 1; 17 de diciembre de 1870, "2; son algunos ejemplos de esas llamadas a la rebelión armada. 
publicaba la siguiente frase: "Cualquier paso que se dé para imposibilitar el reinado del candidato de Prim, nos parece inútil y hasta ridículo fuera del terreno de la fuerza, porque en ese terreno y no en otro ha colocado la cuestión el presidente del Consejo de ministros." 61

Días después, en el número del 11 de noviembre, este diario transcribía una frase de un medio valenciano, El Centro Popular, que afirmaba adherirse "en un todo a esta declaración." ${ }^{62}$ El aviso del diario republicano de emplear la violencia contra el Gobierno $\mathrm{y}$, más especialmente contra su jefe, era más que evidente; sin embargo, si ponemos en el punto de mira a $\mathrm{El}$ Combate, no se debe olvidar que había otros medios que opinaban exactamente igual.

La cuestión es que El Combate continuó en esa línea y, el 8 de noviembre, publicaba lo siguiente:

“ $\mathrm{O}$ ! general Prim, eres ingrato, vengativo y cruel al perseguir a los que más noble y desinteresadamente trabajaron por tu causa, y das pruebas de poseer un alma mezquina al ensañarte con la desgracia. (...) ¿no temes que algún día te pida cuenta y cuenta estrecha y severa el pueblo (...)? No temerás, no, porque estás henchido de vanidad y embriagado por el perfume de la adulación que te eleva a la categoría de los dioses; pero ya te llegará la hora de la espiación [sic], y entonces... ¡ay! tampoco deberá haber compasión para el que no la tuvo ni de sus compañeros de infortunio." 63

Más aún, el 21 de ese mismo mes se refirieron de esta forma a una posible muerte de Prim:

"Con la destrucción de las instituciones y leyes monopolizadoras del bien público y con la muerte de los que a sangre y fuego las sostienen, morirá el despotismo; con el despotismo la injusticia, y con la injusticia la degradación y la miseria que oscurecen el camino del deber y del derecho, pisoteados y desconocidos por la situación verdaderamente terrorista y demagógica del rey Prim, del DICTADOR PRIM. Así opina EL COMBATE." ${ }^{\prime 4}$

Pocos días antes del asesinato de Prim, este diario presumía de sus llamadas a la violencia: "En las columnas de EL COMBATE se ha razonado larga y concienzudamente sobre la necesidad imperiosa e ineludible de un acto de fuerza." 65

Esta frase, aun reconociendo su virulencia y agresividad, será eclipsada en la historiografía por una que ha sido tomada como prueba definitiva de la posible participación de Angulo en el magnicidio. La frase puede leerse en el último número de El Combate que, casualmente, dejó de publicarse justo dos días antes del atentado, con motivo de la desaparición del jerezano: "Cuando la violencia y la fuerza son las únicas armas de un gobierno usurpador, los defensores de los derechos del hombre y de las libertades patrias deben cambiar la pluma por el fusil y repeler la fuerza con la fuerza."66

El cese de las publicaciones del diario, sumado a esta última lapidaria sentencia, y la desaparición de Paúl y Angulo, han provocado que el diputado republicano sea visto como el principal sospechoso del caso Prim. No todos los autores están tan seguros de que Paúl y Angulo participase en la conspiración y justifican sus actos. Uno de ellos es

\footnotetext{
${ }^{61}$ El Combate, 7 de noviembre de 1870, 2.

62 Ibidem, 11 de noviembre de 1870, 3.

${ }^{63}$ Ibidem, 8 de noviembre de 1870, 1-2.

${ }^{64}$ Ibidem, 21 de noviembre de 1870, 1.

${ }^{65}$ Ibidem, 18 de diciembre de 1870, 4.

${ }^{66}$ El Combate, 25 de diciembre de 1870.
} 
Olivar Bertrand, quien piensa que Angulo pudo ocultarse por las causas criminales y denuncias que acumulaba por lo escrito en su periódico. ${ }^{67}$

Esto es cierto y puede comprobarse fácilmente porque en diferentes números del diario republicano se denuncia la persecución que sufrieron pese a existir libertad de expresión e imprenta. ${ }^{68}$

Evitando caer en una interpretación errónea de lo que El Combate publicaba antes del 27 de diciembre al conocer ya el desenlace, lo cierto es que los escritos de Paúl y Angulo constituyen una prueba bastante sólida contra él, (aunque Olivar Bertrand afirma, no sin razón, que se puede ser muy duro con las palabras pero, a la hora de la verdad, no ser capaz de acabar con la vida de una persona a sangre fría). ${ }^{69}$ Además de sus palabras están sus actos, antes y después del magnicidio, que tampoco permiten apartarlo de la posición de principal sospechoso, aunque tampoco se le puede acusar de forma rotunda.

\section{Conclusiones}

En cuanto a la prensa contemporánea al atentado, se puede afirmar que se mostró unánime y nunca dudó en condenar el crimen cometido contra Prim, aunque no todos lo hiciesen con la misma contundencia. Sin embargo, si descendemos al detalle, cada periódico hizo gala de su ideología, y el modo de tratar el atentado varió notablemente de un diario a otro. Así, se puede afirmar que, en este caso, cada medio antepuso la creación de estados de opinión entre sus lectores a la información sincera y veraz. Las tesis de cada uno de los diarios son fácilmente identificables: los medios afectos al gobierno de Prim (La Iberia y El Imparcial), dejaban patente la fortaleza de su Partido, incluso tras la pérdida de su líder indiscutible, y presentaban un general Prim amado y venerado por todos los españoles, que jamás permitirían que su obra se destruyese por medio de revueltas y algaradas. Justo en el extremo contrario se hallaban los periódicos republicanos y democráticos (La Igualdad y La Discusión), que defendían que, muerto Prim, el progresismo español dejaría de existir, (una tesis en la que coincidían con $L a$ Esperanza). Además, su preocupación se centraba en dos aspectos: la sustitución de Prim por el unionista Topete, mucho más alejado políticamente de la ideología republicana; y la, más que posible, pérdida de libertad que acompañaría a la muerte del presidente del Consejo. Los medios conservadores y tradicionalistas (La Época y La Esperanza) mostraban su nerviosismo en torno al orden público. El atentado había tenido lugar por culpa de la incompetencia de un gobierno que estaba descuidando el orden público. La seguridad en las calles y la estabilidad del sistema eran las dos obsesiones principales de estos medios.

La prensa también fue escenario de diversos cruces de acusaciones y sospechas. En primer lugar, los medios hablaban de la presencia de personas sospechosas que deambulaban por el centro de Madrid el día del atentado. Estos recelos apuntalan la tesis que afirma que Prim fue avisado de que se preparaba un nuevo intento de asesinato contra

\footnotetext{
${ }^{67}$ OLIVAR BERTRAND, op. cit., 542. Hay que señalar que el propio Paúl y Angulo empleó, ya en 1886, el mismo argumento que Olivar Bertrand. PAÚL Y ANGULO, op. cit., 152. Otros investigadores han seguido la misma línea exculpatoria del republicano. Pere Anguera escribe que, pese a los violentos ataques del diario que Paúl y Angulo dirigía, no todos llevaban su firma, es más, llega a afirmar que él solo se comprometió a dirigir el periódico "porque estaba protegido por la inmunidad parlamentaria, [Paul Angulo] se oponía a la publicación de los más virulentos.” ¿Quién era, entonces, el autor de los ataques más duros que se vertían sobre el conde de Reus? Anguera lo tiene claro: Francisco Rispa Perpiñà. ANGUERA, op. cit., 624 .

${ }^{68} \mathrm{La}$ sede del periódico fue continuamente amenazada y registrada y sus números secuestrados. El diario lo denunció en múltiples artículos.

${ }^{69}$ Ibidem, 542.
} 
él. ${ }^{70} \mathrm{Si}$ los periodistas se habían dado cuenta de este hecho, es inverosímil pensar que la policía no hubiese sospechado también. ¿Por qué no actuó entonces? Los diarios se limitan a denunciar la escasa presencia policial en la zona, aunque no señalan a nadie que no sea el Gobierno (del que Prim era el máximo responsable), es decir, no exigen responsabilidades a los inmediatos superiores de los agentes: el gobernador civil de Madrid, Rojo Arias, y el ministro de Gobernación, Práxedes Mateo Sagasta, ni mucho menos opinan que ambos pudiesen estar involucrados en el crimen. ${ }^{71}$

En segundo lugar, los que sí fueron tildados de sospechosos, por parte de la prensa, fueron los republicanos. Es cierto que sus opiniones, publicadas especialmente en $E l$ Combate, sumadas a la desaparición de su director, no ayudaban a exculparlos pero las pruebas aportadas contra ellos -al menos en la prensa de diciembre de 1870- no parecen suficientes para probar su participación en el magnicidio. Por otro lado, los que no figuran la prensa de estos días, fueron los partidarios del duque de Montpensier y los agentes del general Serrano, que, en el futuro, acabarán incluidos en la lista de sospechosos principales. En esa lista deberían aparecer los autores de la carta que la viuda de Prim recibió poco tiempo después del suceso. Ese documento es citado por la gran mayoría de periódicos consultados para este trabajo, sin embargo, su eco en la historiografía ha sido mínimo. ${ }^{72}$

Por último, en lo relativo a las noticias acerca de la evolución médica del herido, es curioso que la información transmitida a los españoles (hasta el mismo día del fallecimiento) fuese que no se temía por la vida del general. El Imparcial afirmaba que el día 30, el herido empeoró súbitamente y falleció repentinamente. Sin embargo, medios como El País aseguraban (el 31 de diciembre) que Prim se hallaba gravemente enfermo antes del día del deceso y esa información se ocultó. Es más, el propio diario El Imparcial llegó a reconocer que el estado real del paciente se ocultó por "altas razones de Estado", lo que irritó a medios como La Esperanza. Es posible que no se diesen muchos detalles a la prensa por motivos de seguridad, lo que explicaría la desinformación. Esto supondría la aceptación, por parte del Gobierno, de cierto temor a la reacción de los españoles si se les comunicaba que Juan Prim se hallaba en su lecho de muerte o había fallecido en el momento en el que Amadeo I, nuevo rey de España, cuyo pilar fundamental era Prim, viajaba con destino Cartagena. Todo esto contribuyó a aumentar el misterio que, aún hoy, rodea al crimen.

\section{REFERENCIAS BIBLIOGRÁFICAS}

Fuentes primarias

El Combate, 1870.

El Imparcial, 1870, 1871.

La Discusión, 1870, 1871.

La Época, 1870, 1871.

La Esperanza, 1870, 1871.

La Iberia, 1870, 1871.

\footnotetext{
${ }^{70}$ Prim ya había sufrido dos tentativas de asesinato en los meses de octubre y noviembre de 1870. En este caso, Donézar afirma que Bernardo García, director de La Discusión, entregó al propio Prim una lista de sospechosos el día 26 por la mañana: DONÉZAR, op. cit., 550. Pere Anguera cuenta que la lista fue entregada el mismo día 27: ANGUERA, op. cit., 612.

${ }^{71}$ Años más tarde, Paúl y Angulo, sí acusará directamente a la policía de participar en el asesinato de Prim; sin embargo, en su opinión, los agentes actuaron al servicio del regente, Francisco Serrano. PAÚL Y ANGULO, op. cit., 71-73.

${ }^{72}$ Rueda Vicente la transcribe pero no la comenta. RUEDA VICENTE, op. cit., 297.
} 
La Igualdad, 1870, 1871.

Bibliografía

ANGUERA, Pere, El general Prim. Biografía de un conspirador, Barcelona, Edhasa, 2003.

CALVO POYATO, José, Sangre en la calle del Turco, Barcelona, Plaza\&Janés Editores, 2011.

CAMENO MAYO, Diego, "El bicentenario del general Prim y la polémica sobre su asesinato en los medios de comunicación españoles", RIHC: Revista Internacional de Historia de la Comunicación, 13, 2019, pp. 107-128.

CHECA GODOY, Antonio, El ejercicio de la libertad. La prensa española en el Sexenio Revolucionario (1868-1874), Madrid, Biblioteca Nueva, 2006.

DE CÉSPEDES ARÉCHAGA, Valentín, "El asesinato del General Prim. Revisión de algunos aspectos de lo publicado", Anales de la Real Academia Matritense de Heráldica y Genealogía, 18, 2015, pp. 145-199.

DE DIEGO, Emilio, Prim. Mucho más que una espada, Madrid, Actas, 2014.

DELGADO IDARRETA, José Miguel, "La prensa: fuente historiográfica", Investigación humanística y científica en La Rioja, 2000, pp. 245-256.

DONÉZAR, Javier María, Prim. Un destino manifiesto, Madrid, Sílex, 2016.

FAERNA, Nacho, Prim. El asesinato de la calle del Turco, Barcelona, Espasa, 2014.

FERNÁNDEZ ALBÉNDIZ, María del Carmen, "El Duque de Montpensier y sus aspiraciones a la corona española", Revista de Historia Contemporánea, 8, 1998, pp. 51-76.

FONTANA BERTRÁN, José María, El Magnicidio del General Prim, Astorga, Akrón, 2013.

GARCÍA RODRÍGUEZ, José Carlos, Montpensier. Biografía de una obsesión, Córdoba, Almuzar, 2015.

GIBSON, Ian, La berlina de Prim, Barcelona, Planeta, 2013.

JIMÉNEZ ESCOLANO, Carlos, “...Prim, un crimen sin esclarecer”, Pasea por Madrid: historia, turismo cultural y tiempo libre, 3, 2014, pp. 78-92

LÓPEZ AZORÍN, Fernando, "Un testimonio sobre la participación del diputado José Paúl y Angulo en el atentado contra el general Prim", Boletín de la Real Academia de la Historia, 212, 3, 2015, pp. 481-504.

OLIVAR BERTRAND, Rafael, Prim, Madrid, Tebas, 1975.

PÁUL Y ANGULO, José, Los asesinos del general Prim y la política en España, París, Dentu, 1886.

PEDROL RIUS, Antonio, Los asesinos del general Prim (aclaración a un misterio histórico), Madrid, Civitas, 1990.

PÉREZ ABELLÁN, Francisco, Matar a Prim, Barcelona, Planeta, 2014.

PÉREZ GALDÓS, Benito, España trágica. Madrid, Alianza, 2009.

POCH NOGUER, José, Prim, Barcelona, Editorial Juventud, 1934.

ROBLEDO, María del Mar y KOUTSOURAIS, Ioannis, Las muertes de Prim. Estudio médico legal del general Prim, Madrid, Tébar Flores, 2014.

ROS, Carlos, El duque de Montpensier. La ambición de reinar, Sevilla, Castillejo, 2000.

RUBIO, Javier, Juan Prim; sus años de gobernante, su asesinato: una revisión necesaria, Madrid, Biblioteca Diplomática Española (Ministerio de Asuntos Exteriores), 2017.

RUEDA VICENTE, José Andrés, ¿Por qué asesinaron a Prim?, la verdad encontrada en los archivos, Pamplona, EUNSA, 2000.

VILCHES GARCÍA, Jorge, "Mito y realidad del general Prim", La Ilustración liberal: revista española y americana, pp. 60-61, 2014, https://www.clublibertaddigital.com/ilustracionliberal/60-61/mito-y-realidad-del-general-prim-jorge-vilches.html Fecha de la consulta: 0302-2019. 